\title{
A INFLUÊNCIA DAS EQUIPES DE COMPETIÇÃO NO DESENVOLVIMENTO PROFISSIONAL DOS ESTUDANTES DE ENGENHARIA DO CEFET-MG
}

Pablo H. Santos - pablohsgc@gmail.com CEFET-MG, Engenharia de computação Rua conde de palma, 200 ap 603 - Madre Gertrudes 30512-710 Belo Horizonte, Minas Gerais

Henrique C. Mendes - h8mendes@gmail.com

CEFET-MG, Engenharia de computação

Rua Geraldo Lúcio Vasconcelos, 731 ap 401 - Buritis

30575-859 Belo Horizonte, Minas Gerais

Rosane S. F. Araujo - rosanesfaraujo@gmail.com

CEFET-MG, Engenharia de computação

Rua novo mundo, 663 - Novo Glória

30880-320 Belo Horizonte, Minas Gerais

Kendrick V. M. Cardoso - kendrickvagner@gmail.com

CEFET-MG, técnico de eletrotécnica

Rua Doutor Josias De Araújo Lopes, 134 - Vila Olga

33040-090 Santa Luzia, Minas Gerais

Sandro R. Dias - sandrord@cefetmg.br

CEFET-MG, Departamento de Computação

AV. Amazonas, 7675, Nova Gameleira

30510-000 - Belo Horizonte, Minas Gerais

Resumo: As equipes de competição são grupos de alunos que compartilham experiências $e$ participam de eventos e provas de competição visando desenvolver novas habilidades, aprendizado e qualificações para o mercado de trabalho. Nesse artigo foi buscado por meio de formulário online saber qual a influência das equipes de competição no desenvolvimento profissional dos alunos que fazem parte ou que fizeram parte das equipes. Dos 150 formulários respondidos foi possivel ver que o projeto tem influenciado, motivado e dado oportunidade dos alunos alinharem o conhecimento adquirido em sala a práticas reais das competições, tendo que utilizar de criatividade, trabalho em equipe e demais habilidades necessárias para um engenheiro. Mostrou também que os alunos têm grande expectativa de mesmo sem ter se formado conseguir colocação no mercado de trabalho e motivado a concluírem os cursos de graduação.

Palavras-chave: Equipes de competição. Aprendizado em competições. Qualificações. 


\section{INTRODUÇÃO}

Equipes de competição são grupos formados por alunos da graduação e alunos do ensino técnico. Nelas, os participantes executam atividades extra-curriculares desenvolvendo projetos voltados à sua especialidade (eletrônica, mecânica, programação, entre outras) e os apresentam em eventos de competições gerais.

Este artigo tem por finalidade analisar a influência das equipes de competição no desenvolvimento profissional dos estudantes de engenharia do Centro Federal de Educação de Minas Gerais (CEFET-MG). Segundo (OLIVEIRA;PINTO,2006,p.2) as mudanças tecnológicas aceleraram, essas mudanças afetam surgimento de novos perfis profissionais e novos requisitos para o trabalho de uma maneira geral, e "têm repercussão na formação e qualificação profissional em engenharia, especialmente no que se refere aos cursos de graduação."

O motivo para levantar esse estudo surgiu entre os alunos da graduação, que gostariam de entender um pouco mais sobre os efeitos do envolvimento em projetos competitivos. Dessa forma, surgiu a ideia de verificar o desenvolvimento individual daqueles que já estão inseridos nas equipes ou que tiveram, em períodos passados, a oportunidade de contribuir nelas.

Existem competições diversas como Iron Cup, Shell Eco-marathon, Competição SAE BRASIL AeroDesign e Maratona SBC de Programação. Cada uma possui suas especificações, regulamentos e modalidades. Como exemplo, o regulamento para competições robôs sumôs $3 \mathrm{~kg}$ de 2019 define regras, condutas e critérios para essa categoria e cabem aos participantes atender as máximas estabelecidas no documento. Isso se repete em todos os torneios para evitar abusos e trapaças que poderiam desequilibrar as partidas.

Dentro de um curso de engenharia surgem diversas oportunidades para adquirir conhecimento e experiência como iniciações científicas, artigos de extensão, maratonas individuais e monitorias. Algumas se apresentam mais focados em determinada área e outros são multidisciplinares como as competições. O ponto foi investigar como modalidades tão diferentes, como automobilismo, robótica, programação, aeromodelismo, tecnologias espaciais e eficiência energética podem impulsionar a formação de um aluno de engenharia hoje e tornálo um profissional mais capacitado no futuro.

\section{DESENVOLVIMENTO}

Para melhor análise do assunto, serão abordados os seguintes tópicos: Metodologia, Questões Levantadas e Resultados obtidos. No primeiro, serão expostos os meios científicos usados para a fazer o estudo. No próximo, serão explicadas as questões direcionadas aos participantes, de maneira a justificar sua relevância para a pesquisa. Por fim, serão expostos os resultados obtidos.

\subsection{Metodologia}

Para esse trabalho foram adotados métodos quantitativos de avaliação e os dados foram levantados por meio de formulário online realizado durante a segunda semana de maio de 2020. $\mathrm{O}$ processo de investigação se fundamenta na observação e na pesquisa bibliográfica. Os participantes que responderam ao questionário são membros ou ex-membros de diferentes equipes dentro do CEFET-MG e todos são estudantes de cursos de Engenharia da instituição, Campus I e II, Belo Horizonte. Ao total, 150 alunos participaram da enquete.

As questões abrangem tópicos relacionadas à formação dos participantes, a motivação de permanência na universidade promovida pela equipe de competição, aplicação dos 
conhecimentos obtidos no grupo nas matérias da graduação e avaliação dos alunos quanto ao enriquecimento intelectual proporcionados pelas atividades. As respostas coletadas permitiram a construção de gráficos de setores circulares e barras, que permitiram melhor avaliação dos resultados.

\subsection{Questões Levantadas}

A primeira questão se refere ao curso do aluno. O foco é observar quais cursos estão mais bem representados dentro das equipes. Essa pergunta pode evidenciar quem se beneficia mais das modalidades competitivas abordadas, o que inclusive induz a segunda pergunta. Essa aborda a permanência do aluno no curso em razão da participação no time. "Entre 2001 e 2005, de acordo com cálculos feitos com base em dados do Inep, a taxa anual média de evasão no ensino superior brasileiro foi de 22\%"(INEP ,2006 apud SILVA et al ,2007).

As aulas expositivas com exercícios resolvidos não fornecem o suficiente para o desenvolvimento de habilidade e aprendizagem do aluno (COLENCI, 2000 p. 49). Uma das principais questões que procuramos saber é se os estudantes aplicam o conhecimento obtido em sala nas equipes de competição.

Outra questão a ser estudada é saber se o contato com outras equipes e com a própria equipe de competição tanto nas provas, quanto em eventos proporciona a obtenção de novos conhecimentos relacionados a área estudada na própria graduação, valorizando a interação entre competidores e a troca de experiências.

De acordo com a resolução CNE/CES 11/2002, da Câmara de Educação Superior Art. $3^{\circ}$

$O$ Curso de Graduação em Engenharia tem como perfil do formando egresso/profissional o engenheiro, com formação generalista, humanista, crítica e reflexiva, capacitado a absorver e desenvolver novas tecnologias, estimulando a sua atuação crítica e criativa na identificação e resolução de problemas, considerando seus aspectos políticos, econômicos, sociais, ambientais e culturais, com visão ética e humanística, em atendimento às demandas da sociedade. (DIÁRIO OFICIAL DA UNIÃO,2002,p.32)

será estudado o desenvolvimento de algumas habilidades e competências que estão no Art. $4^{\circ}$. Por fim, buscou-se saber se foram úteis as habilidades e a experiência obtidas para o mercado de trabalho e se o ambiente competitivo das equipes proporcionou um crescimento profissional no estudante.

\subsection{Resultados Obtidos}

O Gráfico 1 mostra a relação dos cursos dentro dos grupos competitivos. Pode-se destacar a grande presença da Engenharia Mecânica, seguida pela Engenharia Elétrica, Engenharia de Computação e Engenharia de Materiais. Em contraste, pode-se verificar a ausência total ou parcial de outros cursos como Engenharia Ambiental e Sanitária, Engenharia de Transportes e Engenharia Mecatrônica. 
Gráfico 1 - Participação por curso

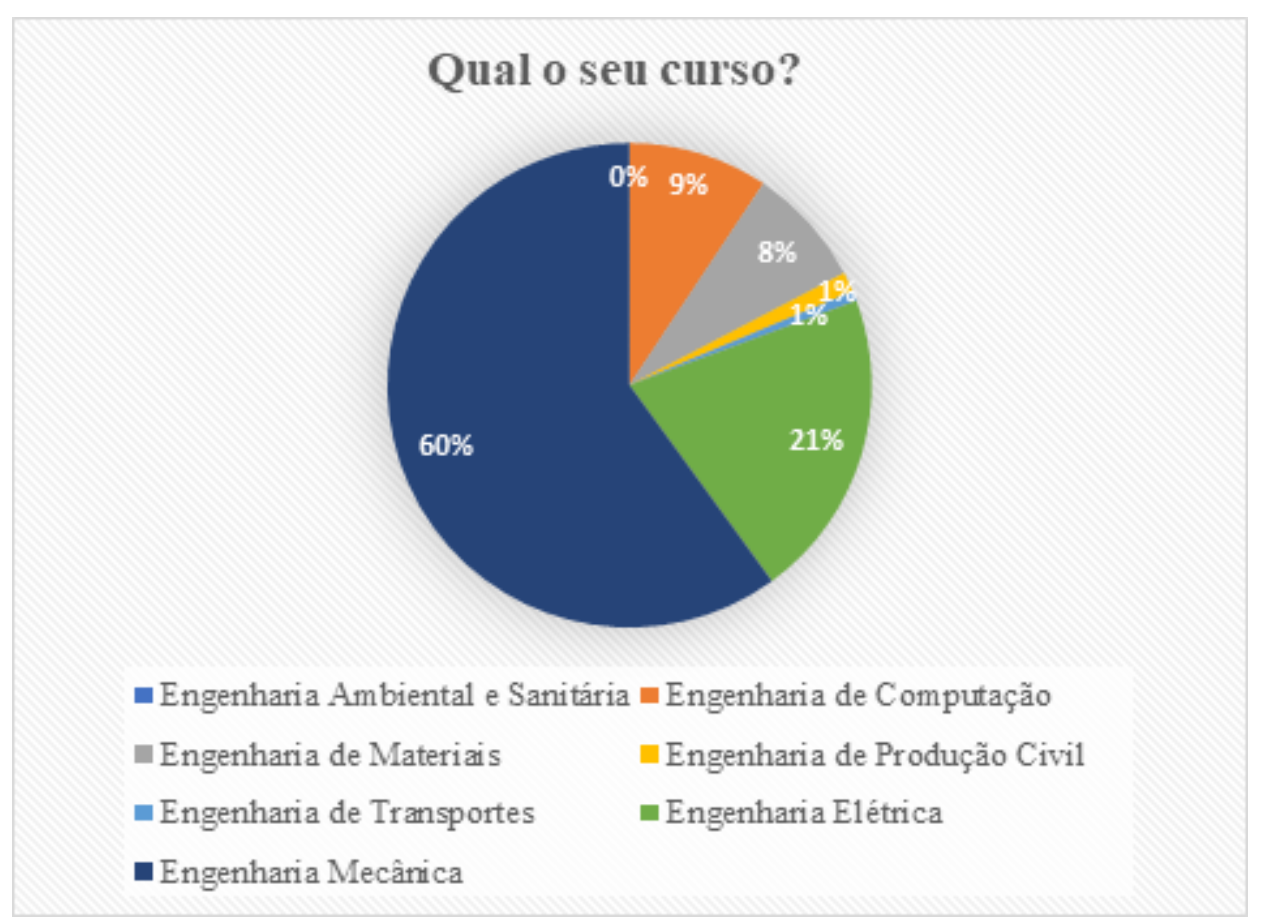

Fonte: Questionário realizado pelos autores

O Gráfico 2 traz dados relacionados à questão de evasão do curso. 89\% encontrou motivação para se manter no curso dentro da equipe, enquanto que quase $9 \%$ sofreram pelo menos uma influência parcial.

Gráfico 2 - Motivação para continuar

\section{A participação nas equipes de competição te motivou/motiva a permanecer no curso?}

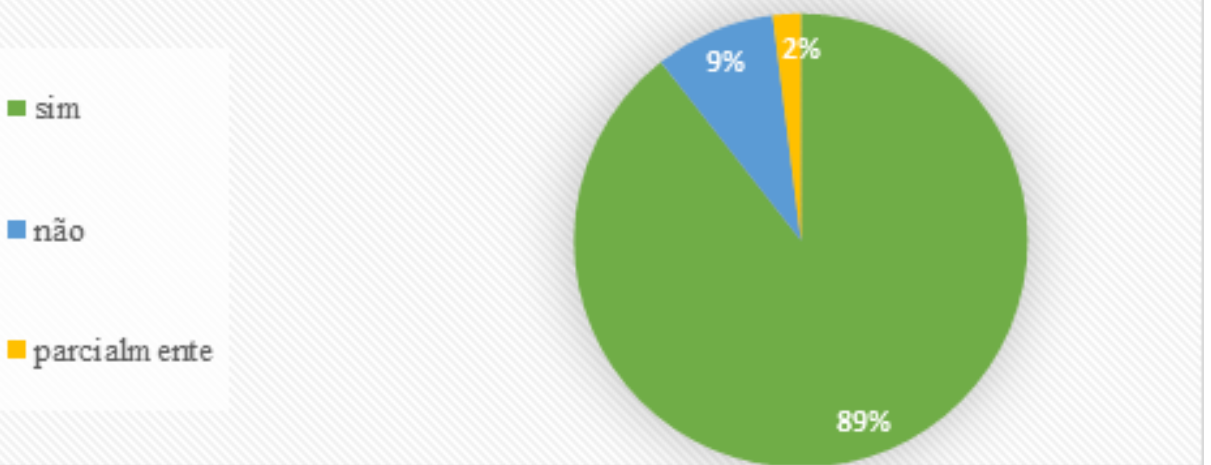

Fonte: Questionário realizado pelos autores

Aliado a motivação, é unânime a visão sobre poder aplicar conceitos do curso nos projetos da equipe. Mesmo entre os membros mais novos e independentemente da área, os conceitos vistos em sala de aula marcam presença em todos as modalidades, como mostra o Gráfico 3. 
"Os desafios para formar hoje o engenheiro do amanhã"

Gráfico 3 - Aplicar conceitos da grade

\section{Foi/É possível aplicar os conhecimentos da grade do seu curso dentro dos projetos da equipe?}

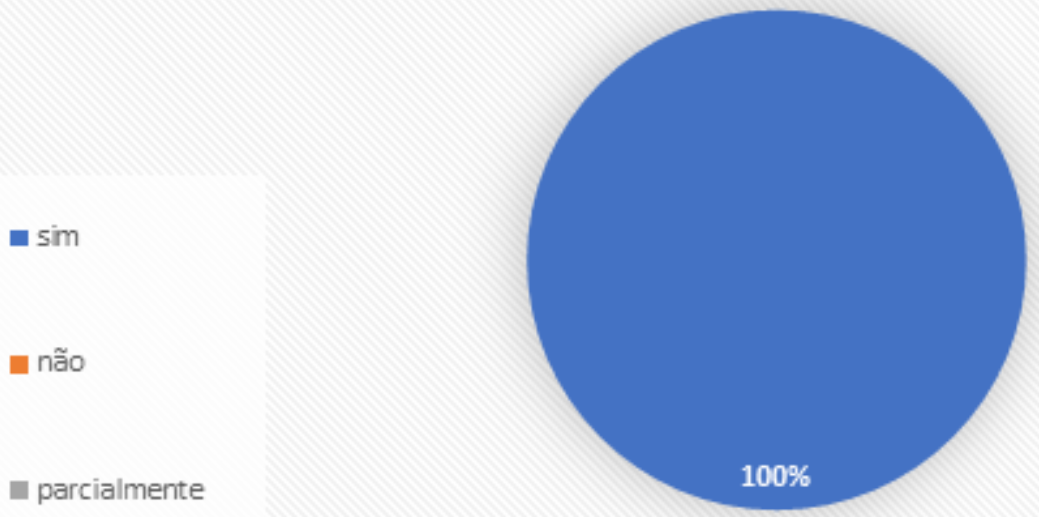

Fonte: Questionário realizado pelos autores

O próximo resultado evidencia a participação dos membros de acordo com a quantidade de campeonatos disputados. Então, pelo Gráfico 4 verifica-se uma distribuição moderada da quantidade de campeonatos disputados por determinada pessoa.

Gráfico 4 - Participação em Eventos

\section{Qual o maior número de eventos competitivos você participou pela mesma equipe?}

$$
\begin{aligned}
& =0 \text { a } 1 \\
& =2 \text { a } 3 \\
& 4 \text { a } 5 \\
& \text { mais de } 6
\end{aligned}
$$

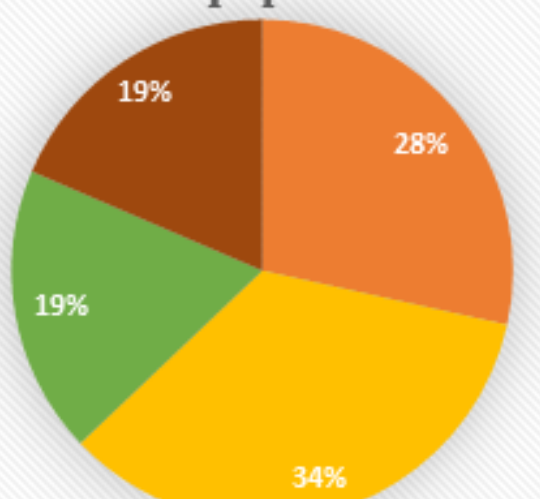

Fonte: Questionário realizado pelos autores

A interação com outras equipes por meio de eventos e competições também tem sido produtiva para maioria dos integrantes. Em eventos, a oportunidade de adquirir novos conhecimentos e estratégias se mostra no Gráfico 5 como realidade. 
"Os desafios para formar hoje o engenheiro do amanhã"

Gráfico 5 - Aprendizado em Eventos

\section{Foi possível durante eventos adquirir novos conhecimentos ao interagir com outras equipes?}

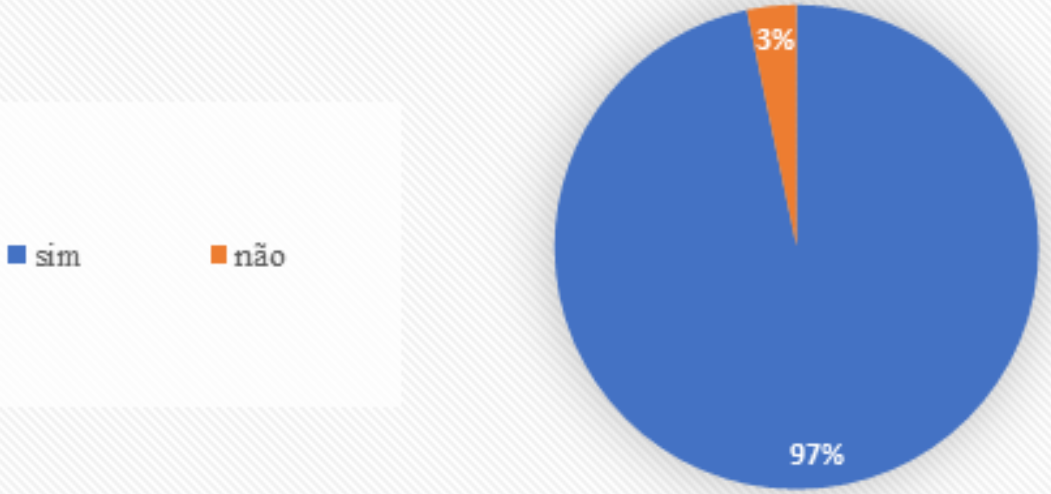

Fonte: Questionário realizado pelos autores

Já no Gráfico 6 ficam evidentes as habilidades que são desenvolvidas e aprimoradas pelos indivíduos das equipes ao fazer parte dos projetos e marcar presença nas competições. Vale mencionar que os participantes podiam escolher mais de uma opção para essa categoria.

Gráfico 6 - Habilidades Aprimoradas

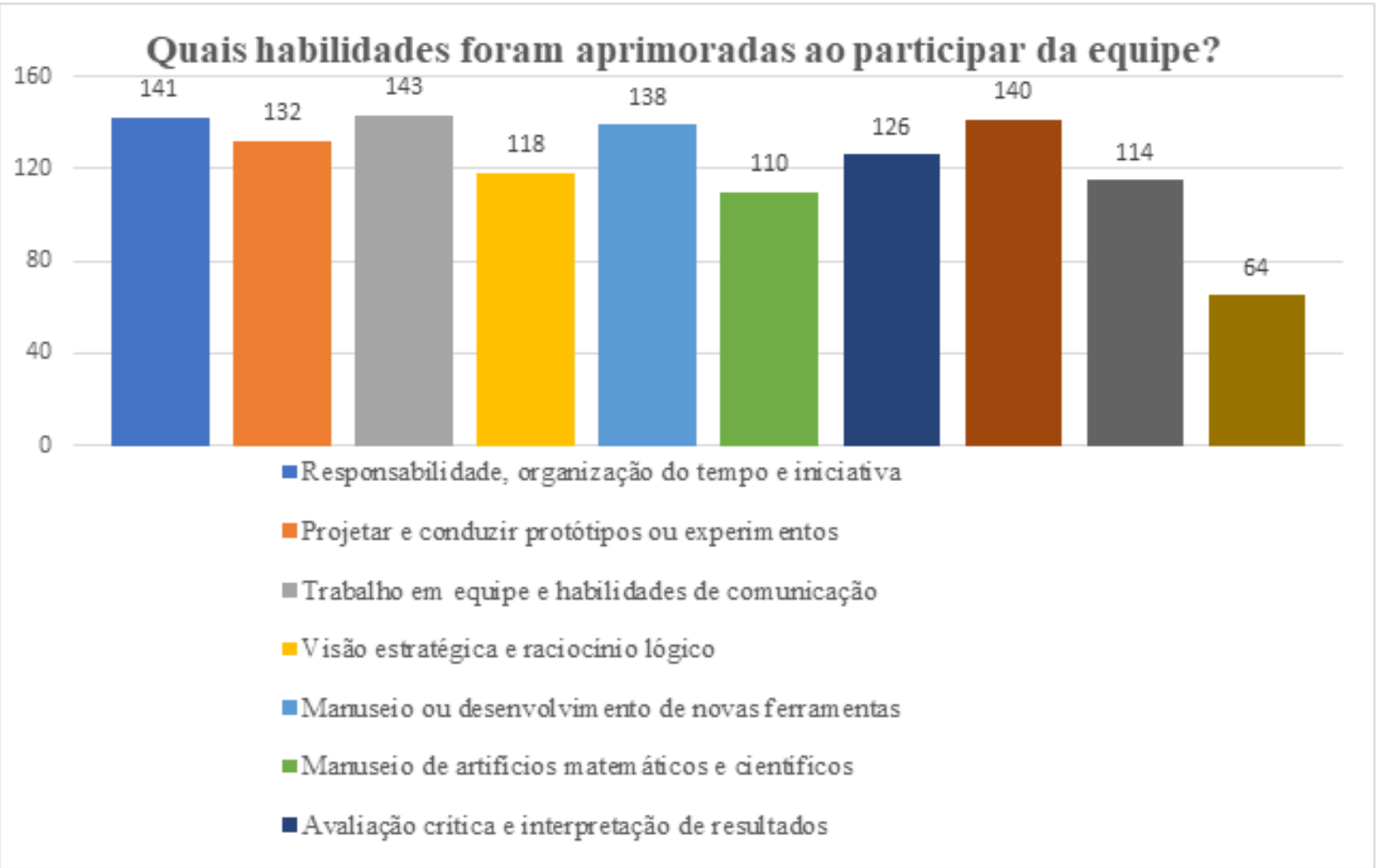

Fonte: Questionário realizado pelos autores

O Gráfico 7 mostra a confiança dos participantes em futuras oportunidades de emprego. Mesmo que não tenha surgido uma oportunidade direta, $99 \%$ enxergam com otimismo o potencial adquirido do ponto de vista profissional. 
Gráfico 7 - Empregos

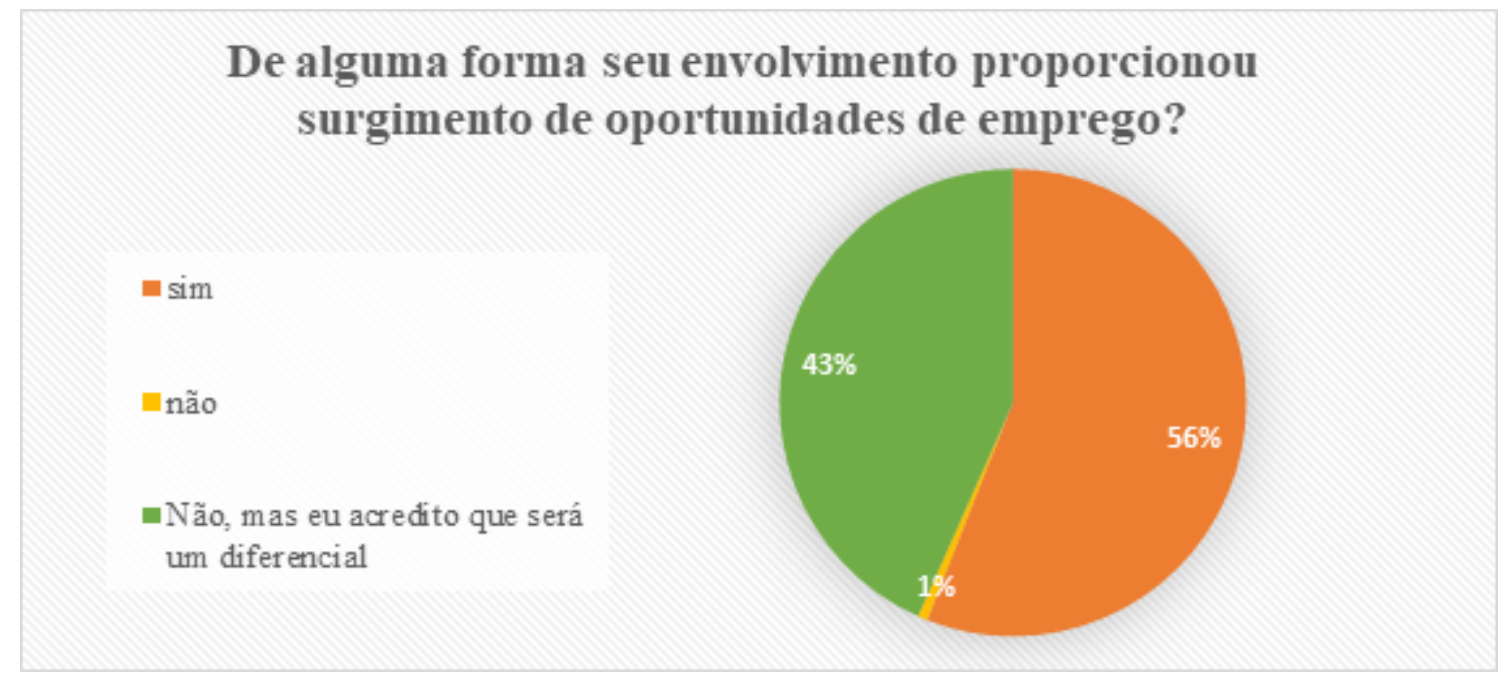

Fonte: Questionário realizado pelos autores

O Gráfico 8 mostra os principais motivos que incentivam as pessoas a entrarem e se manterem em equipes e desenvolverem projetos. Trocas de experiências e motivos profissionais foram as opções mais visadas, mas é evidente o apego emocional em relação a equipe. 
"Os desafios para formar hoje o engenheiro do amanhã"

Gráfico 8 - Principais Motivos Para Participação Em Equipes

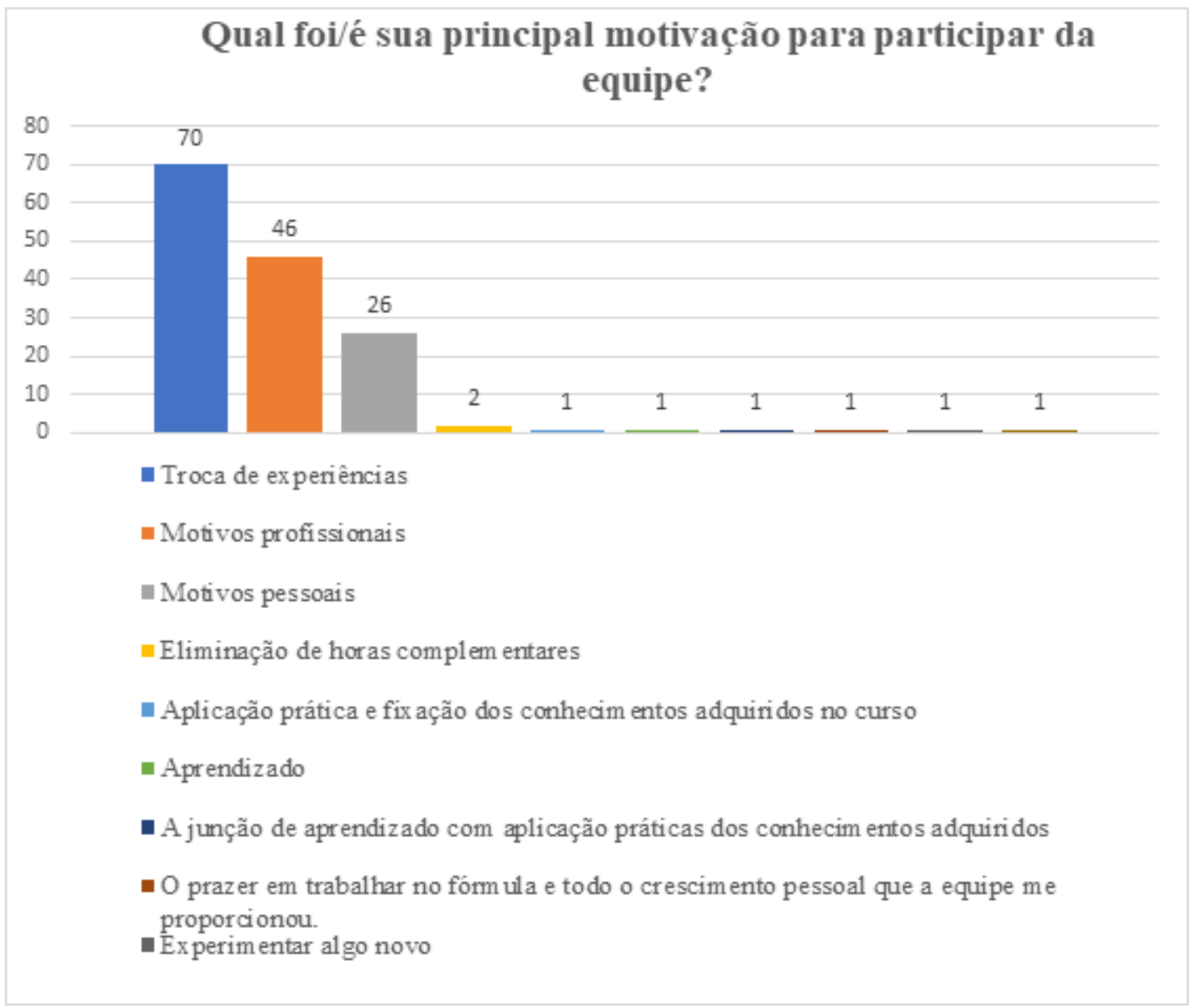

Fonte: Questionário realizado pelos autores

Como último resultado, verifica-se que a maioria dos alunos têm interesses em continuar crescendo e se engajando nesse estilo de trabalho, como mostra o Gráfico 9.

Gráfico 9 - Participação Em Outras Equipes Futuramente

\section{Você participaria de outras equipes de competição?}

" $\operatorname{sim}$ " não

Fonte: Questionário realizado pelos autores 


\section{CONSIDERAÇÕES FINAIS}

Com os resultados dos gráficos, surgiram diversas conclusões positivas sobre a influência das equipes de competição. Uma dessas conclusões foi a de que é possível aplicar o conteúdo da grade curricular de forma impactante para o trabalho da equipe. Não só para isso, as equipes também servem para adquirir novos conhecimentos ao interagir com outras em eventos e aprimoram habilidades que são esperadas de qualquer engenheiro.

Uma outra observação relevante foi que a maioria dos graduandos que participam das equipes de competição são alunos dos cursos do turno integral, com exceção do curso de Engenharia Ambiental e Sanitária, o único do turno integral que não possui aluno em alguma das equipes de competição, conforme os dados obtidos.

Observa-se também o reflexo dos projetos no campo profissional, esses resultados mostram que participar das equipes é considerado pelos alunos um diferencial ao competir por uma vaga de emprego. Ademais, mesmo não tendo concluído a graduação, os membros se sentem otimistas com relação às oportunidades no mercado de trabalho por terem passado por essa experiência. Vale ressaltar também que os motivos para ingressar nesta área foram diversos e as expectativas foram atendidas já que $85 \%$ dos participantes demonstraram interesse em compor outros times competitivos devido à experiência positiva. Somado a isso, pode-se dizer que os grupos ajudaram, mesmo que parcialmente, a evitar evasão do curso.

Além disso, é importante salientar que o escopo da pesquisa pode ser aprofundado futuramente, mas para tanto seria necessário, por exemplo, dados mais substanciais obtidos por dispositivos de busca mais complexos que verificam resultados na prática.

De maneira geral foi possível ver que as equipes deixam os alunos mais confiantes em suas habilidades. Devido a isso acreditam mais na possibilidade de colocação no mercado de trabalho além de se motivarem a permanecer e concluir os cursos de engenharia.

\section{Agradecimentos}

As equipes que tornaram essa pesquisa possível: Cefast Aerodesign, Cefast Aerospace, Cefast Baja, Cefast Fórmula, Ecofet, GCC, Pacific Botz e Trincabotz. Agradecemos também ao CEFET-MG pelo apoio para a participação e apresentação deste trabalho no COBENGE 2020.

\section{REFERÊNCIAS}

DIÁRIO OFICIAL DA UNIÃO. Resolução CNE/CES 11/2002,Brasília, 9 de abril de 2002. Seção 1, p. 32.

COLENCI, Ana Teresa. O ensino de engenharia como uma atividade de serviços: a exigência de atuação em novos patamares de qualidade acadêmica. Dissertação de Mestrado. USP - EESC, 2000.

Iron Cup - Regulamento para Competições de Sumôs de Robôs 3kg. Disponível em: <https://www.robocore.net/upload/attachments/regras_sumo_ajrst_2019_pt_197.pdf>.

Acesso em: 19 mai. 2020.

OLIVEIRA, Vanderlei F.;PINTO, Danilo P. :Educação em engenharia como área do conhecimento.In: XXXIV Congresso Brasileiro de Educação em Engenharia,2006,Passo Fundo.Anais.2006. 
SILVA, Roberto L. L. et al. A evasão no ensino superior brasileiro. Disponível em <https://www.scielo.br/scielo.php?pid=S0100-15742007000300007\&script=sci_arttext> Acesso em 30 mai. 2020.

Maratona SBC de Programação - Sobre. Disponível em: <http://maratona.ime.usp.br/sobre20.html>. Acesso em: 19 mai. 2020.

Shell Eco-marathon Brasil - Sobre. Disponível em: <https://www.shell.com.br/energia-einovacao/ecomarathon/shell-eco-marathon-brasil.html>. Acesso em: 19 mai. 2020.

SAE Brasil AeroDesign - Sobre. Disponível em: <http://portal.saebrasil.org.br/programasestudantis/sae-brasil-aerodesign>. Acesso em: 19 mai. 2020.

\title{
THE INFLUENCE OF COMPETITION TEAMS ON THE PROFESSIONAL DEVELOPMENT OF CEFET-MG ENGINEERING STUDENTS
}

\begin{abstract}
Competition teams are groups of students who share and participate in events and training tests, develop new skills, learn and qualify for the job market. This article was searched through the online form saber which the influence of competition teams on the professional development of students who are or are part of teams. From the 150 forms answered, it was possible to see that the project has influence, motivated and given the opportunity of aligned students or knowledge acquired in the classroom with real competition practices, having to use creativity, teamwork and other skills necessary for an engineer. Also shown that students have great expectations of it without having been trained to get a job and motivated to complete their undergraduate courses.
\end{abstract}

Keywords: Competition teams. Competitive learning. Qualifications. 